\title{
Transepidermal Water Loss in Developing Rats: Role of Aquaporins in the Immature Skin
}

\author{
JOHAN ÅGREN, SERGEY ZELENIN, MATTIAS HÅKANSSON, ANN-CHRISTINE EKLÖF, \\ ANITA APERIA, LENE N. NEJSUM, SOREN NIELSEN, AND GUNNAR SEDIN
}

Department of Women's and Children's Health [J.A., G.S.], Section for Pediatrics, Uppsala University Children's Hospital, S-751 85 Uppsala, Sweden; Department of Woman and Child Health [S.Z., M.H., A.-C.E., A.A.], Karolinska Institute, Astrid Lindgren Children's Hospital, S-171 76 Stockholm, Sweden; and The Water and Salt Research Center [L.N.N., S.N.], University of Aarhus, 8000 Aarhus C, Denmark

\begin{abstract}
In the extremely preterm infant, high transepidermal water loss (TEWL) can result in severe dehydration. TEWL has been attributed to the structural properties of the epidermis but might also be influenced by mechanisms that facilitate water transport. To investigate whether aquaporins (AQP) may be involved in the extreme losses of water through immature skin, we examined the presence and cellular distributions of AQP-1 and AQP-3 in embryonic and adult rat skin by immunohistochemistry. The expression of AQP mRNA in skin was analyzed with the use of semiquantitative reverse transcription-PCR. In rat pups of different embryonic (E) and postnatal (P) ages (days), TEWL and skin hydration were measured. AQP-1 was detected in dermal capillaries, and AQP-3 was abundant in basal epidermal layers. Both AQP displayed several times higher expression in embryonic than in adult skin. TEWL was highest at embryonic day 18 (E18) $\left(133 \pm 18 \mathrm{~g} / \mathrm{m}^{2} \mathrm{~h}\right)$ and lower at E20 $\left(25 \pm 1 \mathrm{~g} / \mathrm{m}^{2} \mathrm{~h}\right)$ and P4 (9 \pm $\left.2 \mathrm{~g} / \mathrm{m}^{2} \mathrm{~h}\right)$. Skin hydration measured as skin electrical capacitance
\end{abstract}

\section{ABSTRACT}

paralleled TEWL, being highest in fetal skin $(794 \pm 15 \mathrm{pF}$ at E18) and decreasing to $109 \pm 11 \mathrm{pF}$ at E20 and to $0 \pm 0 \mathrm{pF}$ at P4. We conclude that, as in infants, water loss through the skin of rats decreases markedly with maturation during the perinatal period. The expression and cellular localization of the AQP are such that they might influence skin hydration and water transport and contribute to the high losses of water through the immature skin. (Pediatr Res 53: 558-565, 2003)

Abbreviations
TEWL, transepidermal water loss
AQP, aquaporin
E, embryonic
P, postnatal
RT, reverse transcription
SEC, skin electrical capacitance

Evaporation from the skin constitutes the major route of water and heat loss in extremely preterm infants early after birth (1). These losses may result in hypothermia, dehydration, and hyperosmolality, the last of which is associated with an increased risk for cerebral bleeding $(2,3)$. Previous observations in very preterm infants indicate that their very high loss of water from the skin, measured as transepidermal water loss (TEWL) $(4,5)$, is a consequence of their poorly developed epidermis $(6,7)$. The formation of an effective epidermal barrier, limiting water permeability, takes place in late gesta-

Received October 29, 2001; accepted September 24, 2002.

Correspondence: Johan Ågren, Department of Women's and Children's Health, Uppsala University Children's Hospital, S-751 85 Uppsala, Sweden; e-mail: johan.agren@kbh.uu.se

This study was supported by the Swedish Research Council Grants 04998 (G.S.) and 03644 (A.A.), the Gillbergska Foundation, HRH the Crown Princess Lovisa's Society for Child Medical Care, the Märta and Gunnar V. Philipsson Foundation, the Samaritan Foundation, the General Maternity Hospital Foundation, the Danish Research Foundation, the European Commission, and the Danish Medical Research Council.

DOI: 10.1203/01.PDR.0000055777.25933.98 tion (8) and has mainly been attributed to the structural maturation of the stratum corneum and its constituents $(9,10)$.

Aquaporin (AQP) water channels have been shown to be extensively distributed throughout different tissues and to allow rapid and regulated transcellular water transport $(11,12)$. Only a few studies on AQP have included skin analyses. AQP-1 and -3 have been identified in adult rat skin by immunohistochemistry (13) and by RNase protection assay (14), providing support for the speculation that AQP might play a role in transepidermal water transport (15). To understand better the mechanism underlying the high TEWL in preterm infants, we investigated the pattern of distribution and gene expression of AQP-1 and -3 in rat skin at different stages of development and related these findings to TEWL and skin hydration.

\section{MATERIALS AND METHODS}

Animals. All experiments were performed on timedgestation Sprague Dawley rats (B\&K Universal, Sollentuna, 
Sweden) of different embryonic (E) and postnatal (P) ages (days). The normal length of gestation of these rats is $22 \mathrm{~d}$, and day 0 was defined as the plug day. In the studies of rat pups delivered preterm, their dams were anesthetized with an intraperitoneal injection of thiobutabarbital $(8 \mathrm{mg} / 100 \mathrm{~g}$ body $\mathrm{wt})$, cesarean section was performed, and measurements of TEWL and skin electrical capacitance (SEC) were undertaken (see below). Whole-thickness skin samples were obtained from rat pups delivered at an embryonic age of $19 \mathrm{~d}$ (E19) and $20 \mathrm{~d}$ (E20) and from adult rats at a postnatal age of $40 \mathrm{~d}$. Skin samples from male Wistar rats (M\&B, Ry, Denmark) were used as preabsorption controls. All skin samples were taken from the back of the rat pups and were immediately frozen on dry ice after removal. The rat pups were suckled by their dams, and the dams and adult rats were fed a standard rat diet (Bantin \& Kingman Ltd, Hull, UK) and received tap water ad libitum. The study was approved by the Uppsala University Animal Ethics Committee.

Primary antibodies. Previously characterized immune serum or affinity-purified (AP) antibodies included AQP-1 (CHIP28 serum or LL266AP, ref 15a), AQP-1 (RA3391/ 2353AP, ref 15b), $A Q P-3$ (LL178AP, ref 15c), and $A Q P-3$ (RA3040/1592AP, ref 15b).

Immunocytochemical localization of AQP-1 and AQP-3. After fixation, immunohistochemical analysis was performed using thin cryosections $(10-12 \mu \mathrm{m})$ or thin paraffin sections (2 $\mu \mathrm{m})$ incubated with antibodies against the different AQP (800 $\mathrm{ng} \operatorname{IgG} / \mathrm{mL})$. The labeling was visualized as previously described (16), using horseradish peroxidase-conjugated secondary antibodies (P0448, DAKO, Denmark; diluted 1:100). Controls in which the antibodies were preabsorbed with the immunizing peptides displayed no labeling.

Semiquantitative analysis of $A Q P-1$ and $A Q P-3 m R N A$ expression. Skin samples $(\sim 30 \mathrm{mg}$ each $)$ from $\mathrm{E} 19(\mathrm{n}=6)$ and adult $(n=6)$ rats were obtained for extraction of total RNA using RNeasy Mini Kit (QIAGEN, Hilden, Germany). The yield of total RNA was measured with a spectrophotometer (Beckman DU 640, Fullerton, CA, U.S.A.).

Reverse transcription (RT) was carried out in a $20-\mu \mathrm{L}$ reaction volume containing $3 \mu \mathrm{g}$ of total RNA, standard MMLV RT buffer (Promega, Madison, WI, U.S.A.), $40 \mathrm{ng}$ of oligo-dT15 (Promega), $1 \mathrm{mM}$ dNTP (Amersham Pharmacia Biotech, Little Chalfont, UK), $60 \mathrm{U}$ of rRNasin (Promega), and $300 \mathrm{U}$ of MMLV RT (Promega) and incubated for $60 \mathrm{~min}$ at $42^{\circ} \mathrm{C}$. The RT reactions were terminated by inactivation at $65^{\circ} \mathrm{C}$ for $10 \mathrm{~min}$ and followed by chilling to $4{ }^{\circ} \mathrm{C}$.

Five microliters of the RT reaction was converted to a $50-\mu \mathrm{L}$ PCR mixture containing standard PCR buffer (Promega), 2.5 $\mathrm{mM} \mathrm{MgCl} 2,0.2 \mathrm{mM}$ each dNTP (Amersham Pharmacia Biotech), $0.6 \mu \mathrm{M}$ AQP-1 primers (or $0.8 \mu \mathrm{M}$ AQP-3 primers), 0.4 $\mu \mathrm{M}$ Classic II Internal Standards (Ambion, TX, U.S.A.), and $10 \mathrm{U}$ of AmpliTaq Gold (Perkin Elmer, Foster City, CA, U.S.A.). The PCR mixtures were divided into three reactions of $15 \mu \mathrm{L}$ each and subsequently amplified in 26,28 , and 30 cycles $\left(94^{\circ} \mathrm{C}\right.$ for $30 \mathrm{~s}, 65^{\circ} \mathrm{C}$ for $\left.1 \mathrm{~min}\right)$, starting at $95^{\circ} \mathrm{C}$ for $8 \mathrm{~min}$ and finishing at $65^{\circ} \mathrm{C}$ for $5 \mathrm{~min}$.

The PCR products were run on $1.5 \%$ agarose gel with $1 \times$ TAE buffer, containing $0.5 \mu \mathrm{g} / \mathrm{mL}$ GelStar stain (BioWhittaker
Molecular Applications, Rockland, ME, U.S.A.). GeneRuler 100 bp DNA ladder (Fermentas, Vilnius, Lithuania) was used for sizing of PCR fragments. Digital images were acquired with use of a Fluor-S MultiImager and analyzed with the original software (Quantity One, version 4.2.1, Bio-Rad Laboratories, Hercules, CA, U.S.A.) after subtraction of matched backgrounds.

All reaction solutions (except RNA and cDNA, rRNasin, MMLV RT) in semiquantitative RT-PCR were premixed to eliminate errors during pipetting. All RNA samples were analyzed at least three times. The level of 18S rRNA expression was measured in all samples and used to normalize the AQP expression, thus correcting for any sample-to-sample differences in RNA concentration, RNA quality, and efficiency of the RT and PCR reactions. The values for AQP expression are presented as the ratio of $\mathrm{AQP} / 18 \mathrm{~S}$ signals.

Primer design. The primers for AQP-1 and AQP-3 were designed on the basis of their reported sequences and obtained from CyberGene (Huddinge, Sweden). The AQP primers were selected from different exons to avoid amplification of genomic DNA. The Classic II 18S Internal Standards (Ambion) primer set was used as internal control, according to the manufacturer's protocol. The size of the $18 \mathrm{~S}$ PCR fragment is $324 \mathrm{bp}$. The AQP-1 and AQP-3 primers are specified in Table 1.

$\boldsymbol{T E} \boldsymbol{W L}$. The rate of evaporation of water (TEWL;g/ $\mathrm{m}^{2} \mathrm{~h}$ ) from the skin surface was measured in $\mathrm{E} 18(n=8), \mathrm{E} 20(n=$ $4)$, and P4 $(n=10)$ rats, with a previously described method $(17,18)$, using the Evaporimeter (Ep1, Servomed, Stockholm, Sweden), which also provides data on relative humidity and water vapor pressure $\left(\mathrm{PH}_{2} \mathrm{O}\right)$. The evaporimeter calculates TEWL by measuring $\mathrm{PH}_{2} \mathrm{O}$ and temperature at two points at different distances from the skin surface during free evaporation. The evaporimeter probe was held lightly against the skin during measurement. After delivery, the fetus was cautiously removed from the amniotic sac with its placental connection intact. The fetus was handled carefully with a sterile compress and placed in the prone position without wiping the skin surface area. TEWL measurements were then made from the upper back of all rat pups every 2 min until a stable level was recorded, which occurred 8-12 min after delivery. In postnatal (P4) rats, which were born at term, TEWL was measured every 2 min during a 10 -min period. During that period, the TEWL values obtained remained stable and the mean of the last two values was calculated. The evaporation rate depends to a large extent on the environmental humidity and temperature $(1,17)$. Accordingly, the evaporimeter probe was also used to measure relative humidity and $\mathrm{PH}_{2} \mathrm{O}$ in the air $10 \mathrm{~cm}$ above the animal, where the air temperature was also measured, using a telethermometer and probe (YSI, Yellow Springs, OH, U.S.A.),

Table 1. $A Q P-1$ and $A Q P-3$ primers used in the $P C R$

\begin{tabular}{|c|c|c|c|}
\hline Name & Structure of primer & $\begin{array}{l}\text { Size of PCR } \\
\text { fragment }\end{array}$ & $\begin{array}{c}\text { Ratio of } 18 \mathrm{~S} \text { primer } \\
\text { pair:competimers }\end{array}$ \\
\hline rAQP1.U & cctttggtctgagcatcgctactc & $614 \mathrm{bp}$ & $3: 7$ \\
\hline rAQP1.L & cctctatttgggettcatctccac & & \\
\hline rAQP3.U & gagatgetccacatccgctac & 484 bp & $1: 3$ \\
\hline rAQP3.L & cacacaataagggetgctgtgc & & \\
\hline
\end{tabular}


ensuring that all measurements were made under similar environmental conditions (data not shown). The measurements were made from a slightly smaller skin surface area than in measurements in infants by reducing the area of skin from which evaporation could take place, and the readings were therefore recalculated so as to be valid for the skin area exposed without affecting the accuracy of the method (Öberg PÅ, personal communication).

Skin hydration. Skin hydration was assessed by determining the SEC, using the NOVA dermal phase meter DPM 9003 (NOVA Research Corp, Gloucester, MA, U.S.A.) with a 3-mm probe (19). The NOVA instrument consists of a spring-loaded probe with two concentric brass rings separated by a nonconducting material and operates between 90 for a low and 999 for a high reading, expressed as an arbitrary value of picoFarad equivalents $(\mathrm{pF})$. The probe was held lightly against the skin, and the SEC value recorded shortly (5 s) after its application to the skin was considered to reflect baseline hydration of the skin (20). SEC was measured intermittently as described for the
TEWL measurements, on the skin of the lower back of the rat pups, caudal to the area where TEWL was measured. When a stable level was reached, the mean of the last two values was calculated.

Treatment of data. Values are presented as means \pm SD. Student's $t$ test on unpaired observations was used to test for statistical significance. $P<0.05$ was considered statistically significant.

\section{RESULTS}

AQP distribution. Immunohistochemical analysis of E20 and adult rat skin revealed that AQP-1 and AQP-3 were abundantly expressed prenatally at day 20 and in adult skin. Representative slides are displayed in Figures 1 and 2. The AQP were found not to be coexpressed; AQP-1 staining was observed exclusively in dermal capillaries in both E20 (Fig. 1, $\mathrm{A}$ and $\mathrm{B}$ ) and adult skin (Fig. 1, C and D). The staining of
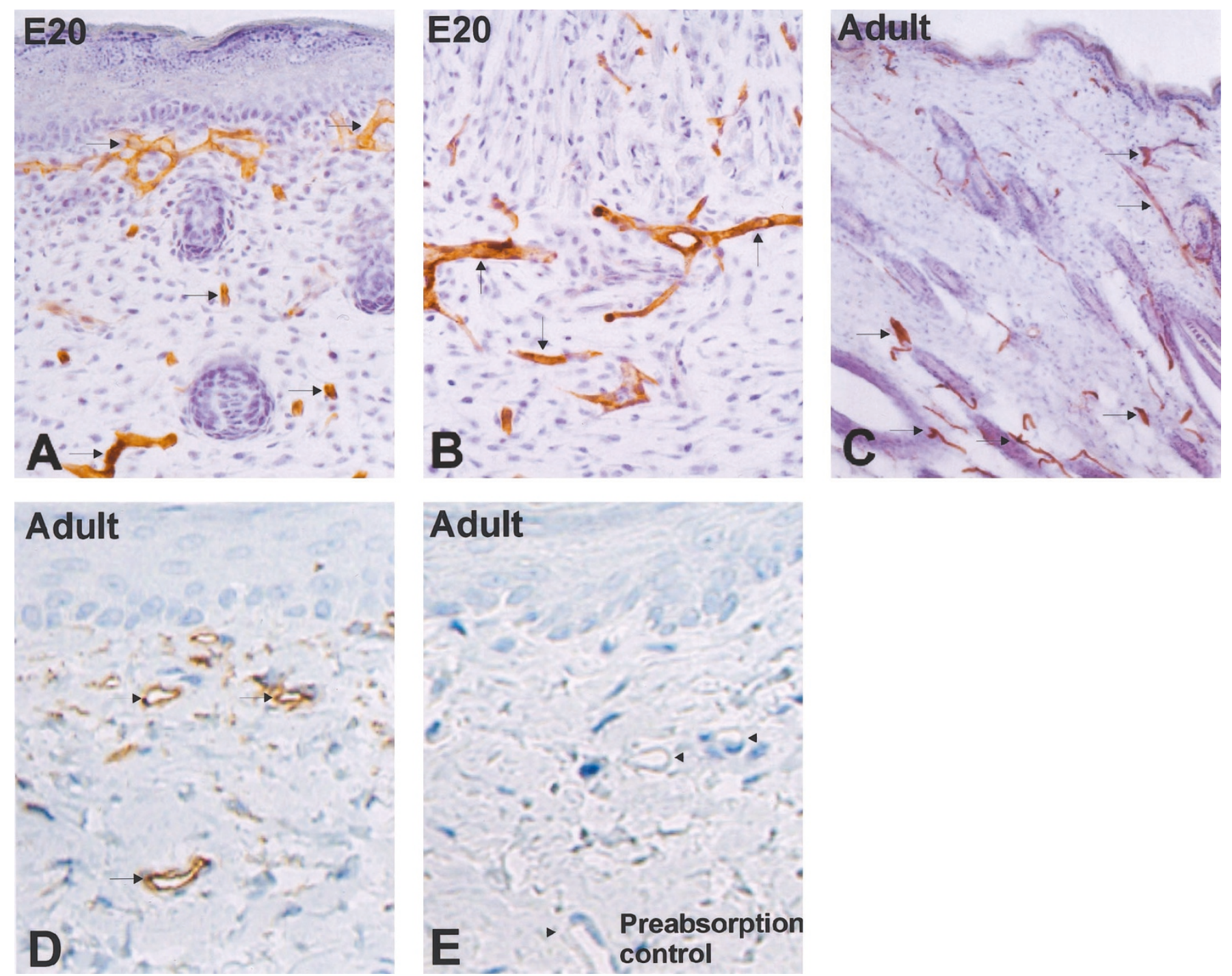

Figure 1. Immunocytochemical localization of AQP-1 in rat skin at E20 $(A$ and $B)$ and in adult $(C$ and $D)$ rat skin. AQP-1 is present in dermal capillaries (arrows). A control using the AQP-1 antibody preabsorbed with immunizing peptide $(E)$ shows no labeling (arrowheads). Immunoperoxidase staining, $\times 100$ $(A$ and $C)$ and $\times 250(B, D$, and $E)$. 

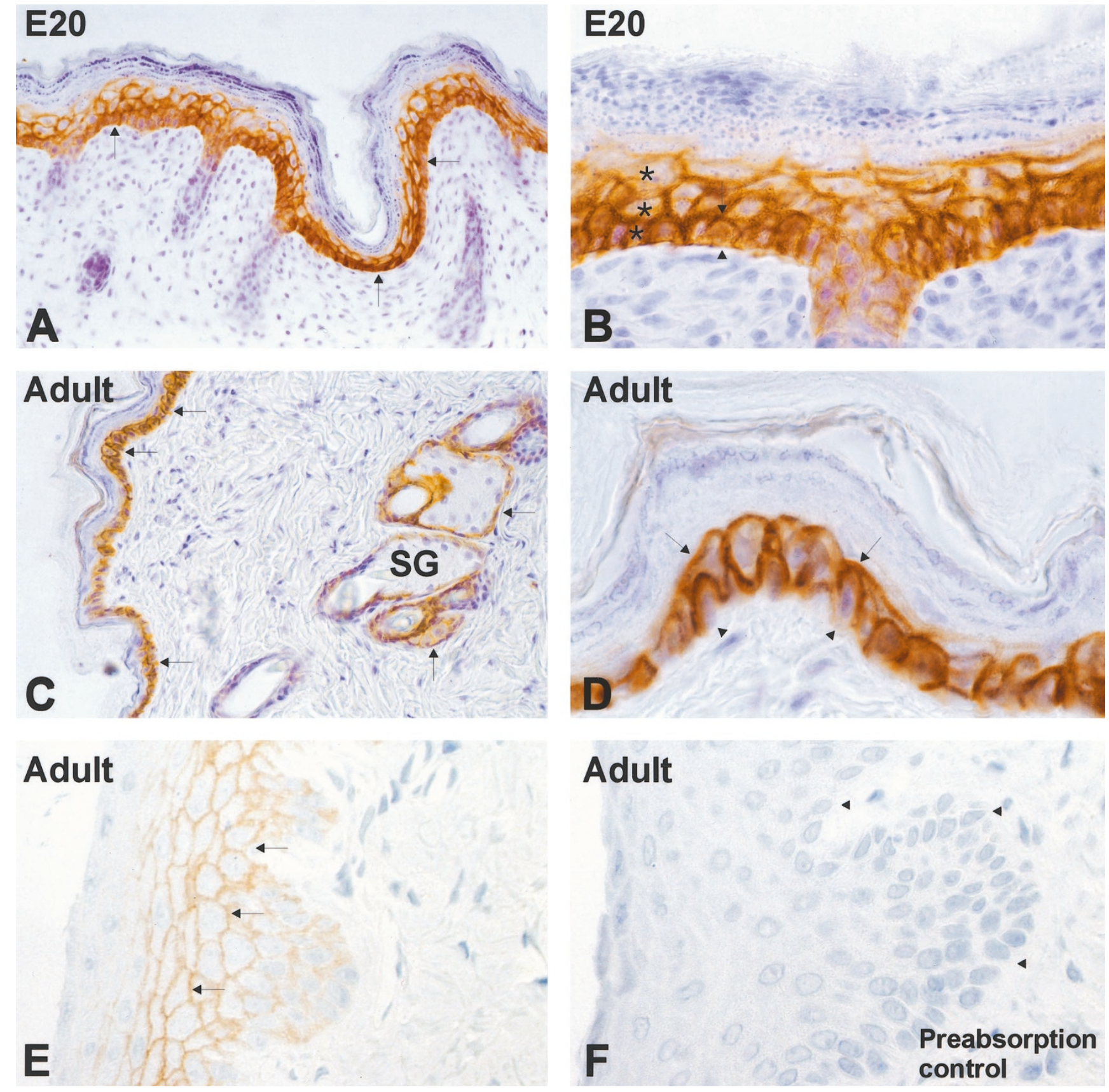

Figure 2. Immunocytochemical localization of AQP-3 in rat skin at $\mathrm{E} 20(A$ and $B)$ and adult $(C-E)$ rat skin. $\mathrm{AQP}-3$ is present in apical-lateral plasma membranes of basal cell layers (arrows) but not in basolateral plasma membranes (arrowheads). A control using the AQP-3 antibody preabsorbed with immunizing peptide $(F)$ shows no labeling (arrowheads). Asterisks in $B$ indicate each stained cell layer in E20 epidermis. SG, sebaceous gland. Immunoperoxidase staining, $\times 100$ $(A$ and $C), \times 250(B, D-F)$.

AQP-1 was denser at E20 than in adult skin because of the relatively higher abundance of capillaries in the immature skin.

Most interesting, AQP-3 was expressed in the epidermis. In E20 skin, the expression was more abundant and localized to the plasma membrane of the two to four basal cell layers of the epidermis (Fig. 2, A and B). In adult rat skin, AQP-3 expression was less abundant; here it was localized to the most basal cell layer and was also found in sebaceous glands and hair follicles (Fig. 2, C-E). The staining of the basal cell layers was seen in the apical-lateral plasma membrane. No staining was observed in the most superficial layers of the epidermis. An immunolabeling control using the antibody preabsorbed with the immunizing peptide showed no labeling for either AQP-1 (Fig. 1E) or AQP-3 (Fig. 2E).

AQP mRNA expression. We determined the level of expression of the AQP-1 and AQP-3 transcripts in E19 and adult rat skin using the semiquantitative RT-PCR method. The specificity of the RT-PCR products was documented by highresolution gel electrophoresis, which resulted in a single product with the desired size (AQP-1, 614 bp; AQP-3, 484 bp; 
Classic II 18S, $324 \mathrm{bp}$ ). When the reverse transcriptase was omitted from the RT reaction solution, no specific products appeared, confirming that the PCR fragments were produced from mRNA and not from contaminating genomic DNA. For ensuring that the analyses of the specific cDNA fragments were made in the range of linear amplification, the PCR was terminated at three different cycles. We found 30 cycles to be well within the range of linear amplification of the PCR.

The expression of AQP-1 and AQP-3 mRNA was several times higher in embryonic than in adult skin. It is presented as the ratio of $\mathrm{AQP} / 18 \mathrm{~S}$ signals in Figure 3 (top). At E19, the ratio for AQP-1 was $1.5 \pm 0.4$ and for AQP-3 was $2.5 \pm 0.3$. The corresponding values in adult skin were $0.2 \pm 0.1$ and $0.6 \pm$ 0.2 , respectively. The differences between E19 and adult skin were statistically significant for both AQP $(p<0.001)$. Samples of typical agarose gel appearances are displayed in Figure 3 (bottom).

TEWL and SEC in relation to maturity. TEWL and SEC were measured from the skin of E18, E20, and P4 rats. TEWL was highest at E18 $\left(133 \pm 18 \mathrm{~g} / \mathrm{m}^{2} \mathrm{~h}\right)$ and then decreased
A

AQP-1
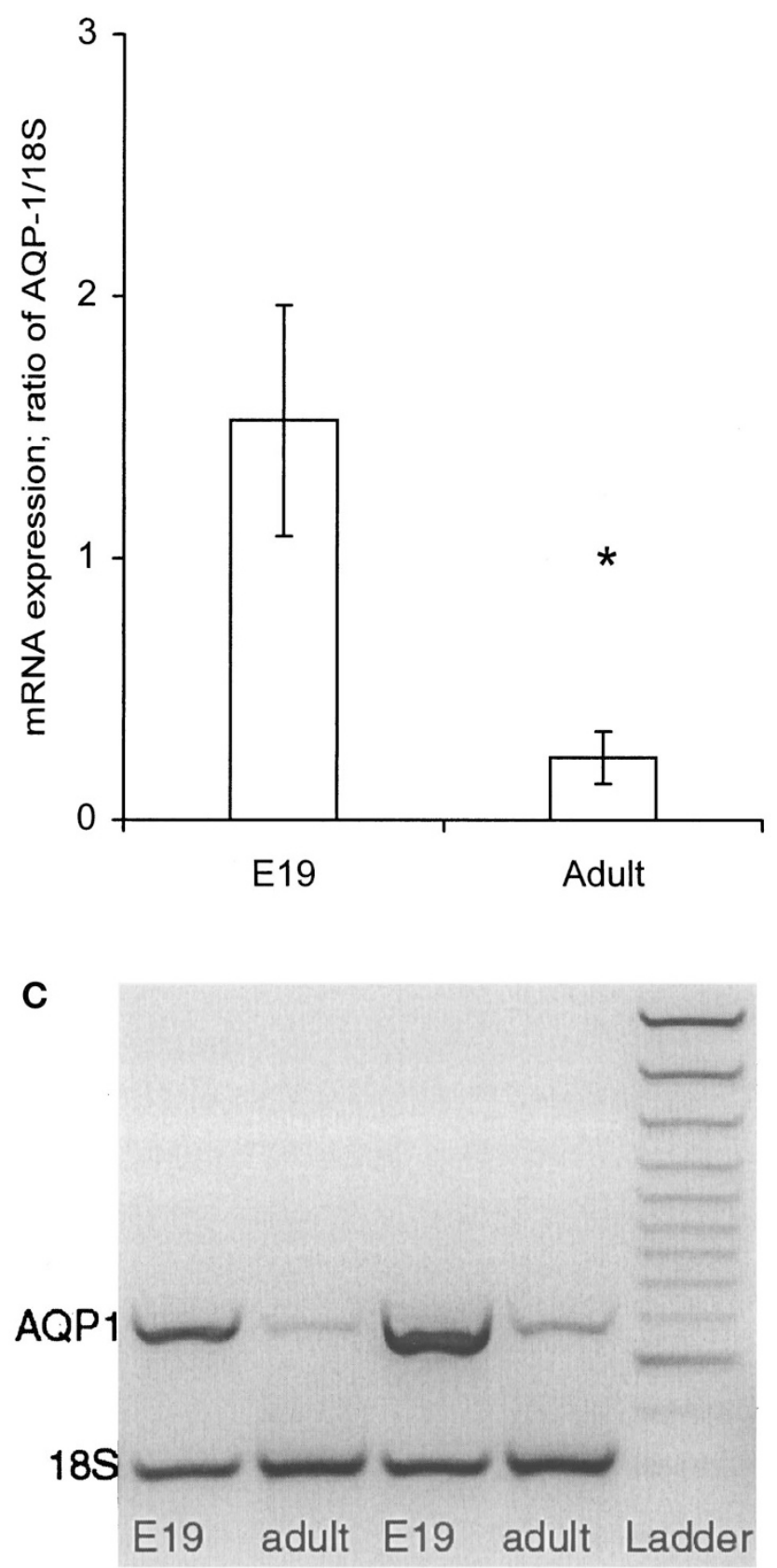

B

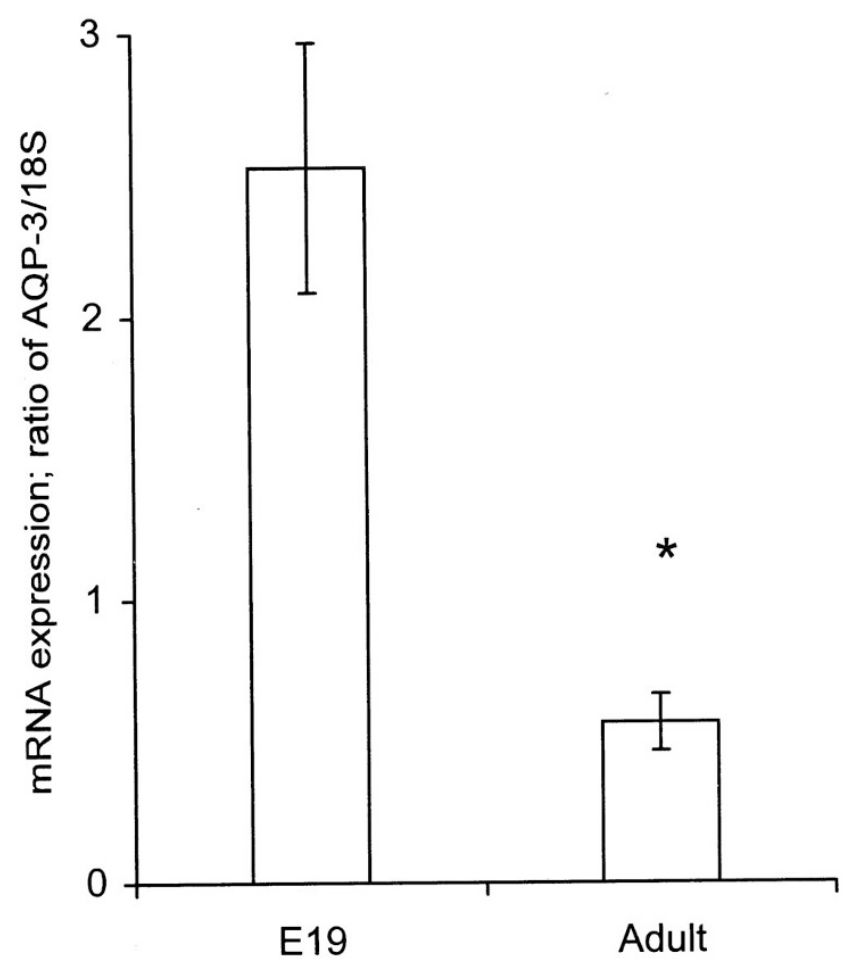

D

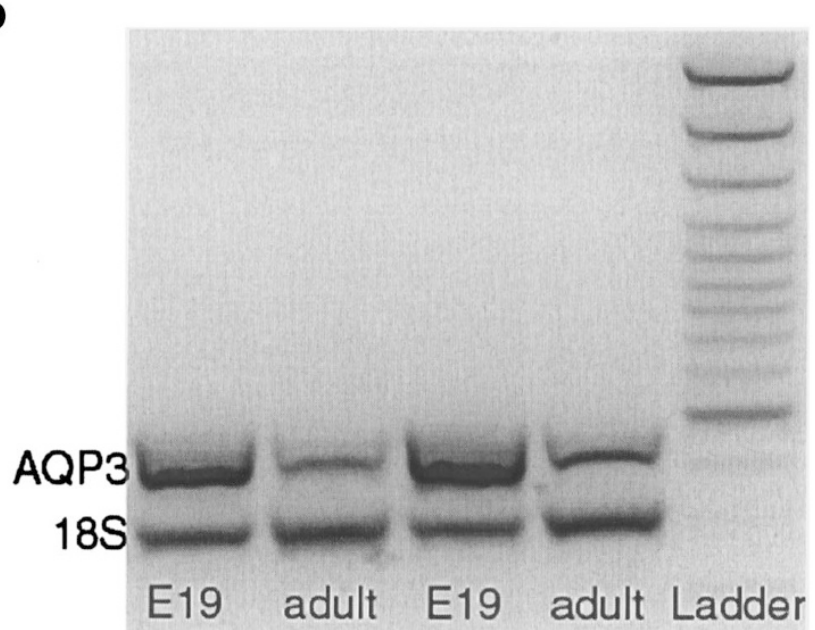

Figure 3. AQP-1 and -3 mRNA expression in embryonic (E19) and adult rat skin (top) and corresponding representative examples of the agarose gel appearance (bottom). Values are presented as the ratio of AQP/18S RNA signals \pm SD. Asterisks indicate statistical significance $(p<0.001)$ 
markedly, reaching $25 \pm 1 \mathrm{~g} / \mathrm{m}^{2} \mathrm{~h}$ at E20 ( $p<0.001$; Fig. 4). There was an even further reduction in TEWL at P4 to $9 \pm 2$ $\mathrm{g} / \mathrm{m}^{2} \mathrm{~h}(p<0.001$; Fig. 4). SEC as a measure of skin hydration was also related to maturity, being $794 \pm 15 \mathrm{pF}$ at E18, $109 \pm$ $11 \mathrm{pF}$ at E20, and $0 \pm 0 \mathrm{pF}$ at $\mathrm{P} 4(p<0.001$; Fig. 5).

\section{DISCUSSION}

As in infants, the present study demonstrates that in rats, water loss through the skin and skin hydration decrease with increasing maturity at birth and with increasing postnatal age. Thus, our experimental method can be used to study the cellular and molecular mechanisms underlying the extreme losses of water through the skin of newborn very preterm infants. Two forms of AQP are abundant in perinatal rat skin, namely AQP-1 and AQP-3. AQP-1 is localized in dermal capillaries, with higher expression before birth than in the adult rat. AQP-3 is present in the basal cells of the epidermis and is much more abundantly expressed in fetal than in adult skin.

This study clearly demonstrates the similarity in evaporation of water from human and rat skin during maturation. As in infants $(1,4)$, the amount of water lost from the skin of rat pups is inversely related to both gestational and postnatal age. The gradient method used for determination of TEWL $(1,18)$ in the present study allows measurement of free evaporation from the skin surface under physiologic conditions and permits accurate determinations of both low and very high evaporation rates. We consider our experimental method using the developing rodent to be a valuable tool in studies of epidermal water permeability and in this respect to be relevant to human skin biology. Aszterbaum et al. (9) reported an improvement in rat skin barrier function with advancing maturity. These authors

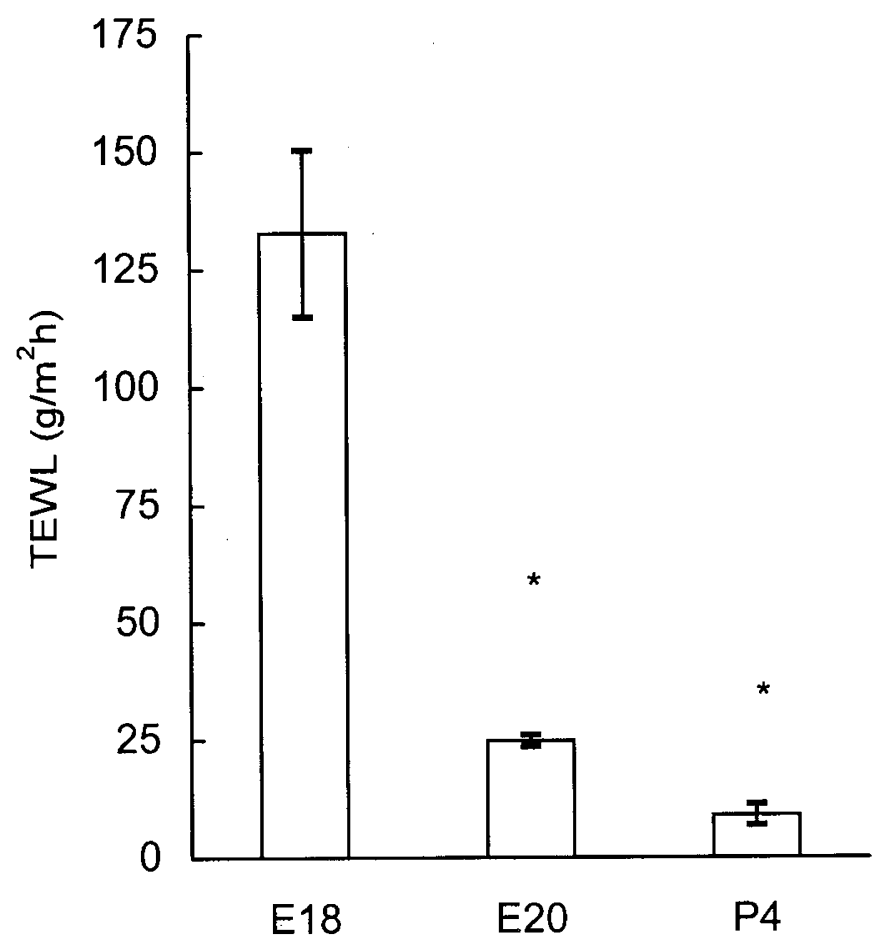

Figure 4. TEWL $\left( \pm \mathrm{SD} ; \mathrm{g} / \mathrm{m}^{2} \mathrm{~h}\right)$ in rats in relation to embryonic $(\mathrm{E})$ and postnatal (P) age (days). Asterisks indicate statistical significance $(p<0.001)$.

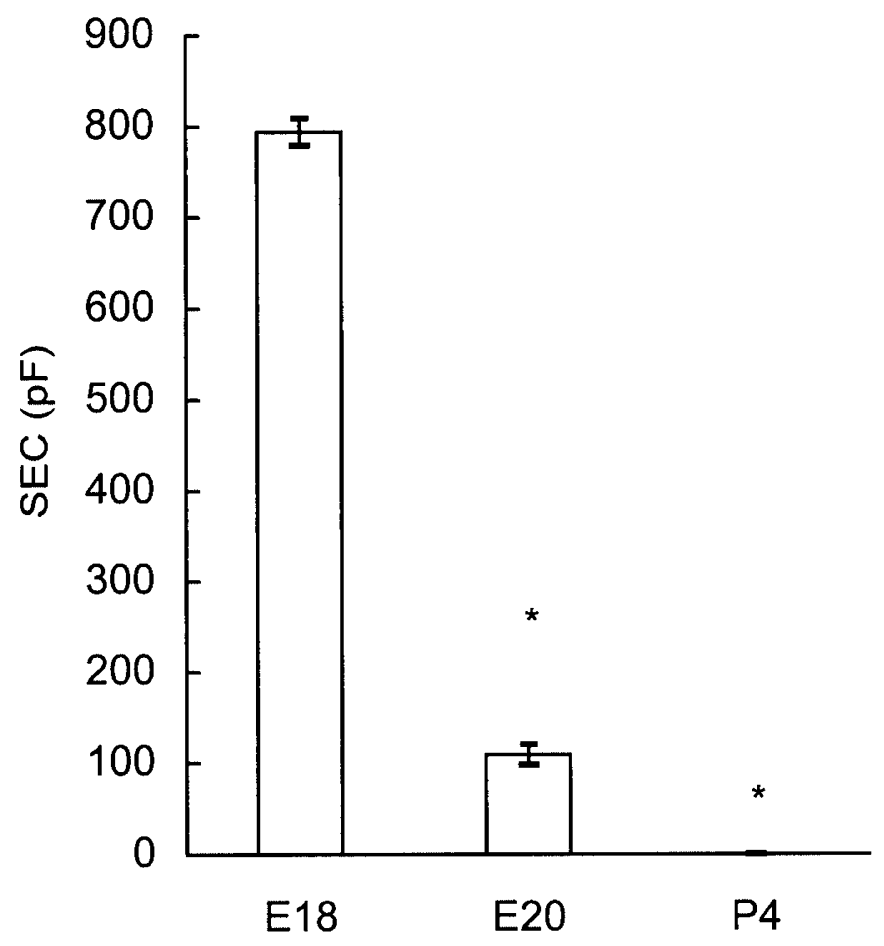

Figure 5. SEC $( \pm \mathrm{SD} ; \mathrm{pF})$ in rats in relation to embryonic $(\mathrm{E})$ and postnatal (P) age (days). Asterisks indicate statistical significance $(p<0.001)$.

proposed that barrier formation in the rat takes place at $\sim 20 \mathrm{~d}$ of gestation. The data from the present study do not support the concept of a specific day of barrier formation. In parallel with the findings in infants $(1,7)$, the development of an epidermis with low water permeability in the rat seems to be a gradual process. The present observation that the hydration of the skin was highest in the immature rats and decreased with maturation is in accordance with previous reports on hydration of both human and rat skin $(21,22)$.

In general, the rate of evaporation of water from the skin is to varying degrees limited by several factors, for example the thickness, structure, and content of the epidermis (8) and the water vapor pressure of the surrounding air (1). In fetal rats, the development of the epidermal barrier has been shown to correlate with the development of the stratum corneum structure and with the lipid content $(9,23)$. Exposure to a dry environment has been reported to result in accelerated maturation of the epidermis in fetal rat skin explants (24) and in adult mice (25). In preterm infants, exposure to the extrauterine environment has also been shown to have a maturational effect on the epidermal structure (7), although functional studies of the skin of extremely preterm infants have clearly demonstrated that TEWL remains high several weeks after birth (5). Extremely preterm infants often display a transient hyperosmolarity during the first days after birth even when they are nursed in incubators with a high humidity (26). It is not clear whether the high transepidermal water losses seen in these infants early after birth can be explained solely by the poor physical barrier of the immature epidermis or whether other mechanisms that facilitate water transport might be involved.

The mechanisms of water flux through cellular membranes were not well understood until the discovery of the AQP in 
$1991(27,28)$. The AQP, which are integral membrane proteins with selective permeability to water, have provided a molecular explanation for several processes involving transcellular transport of water in many different tissues $(29,30)$. Several homologous proteins in the AQP family have been identified, and two major groups of AQP have been described $(29,30)$. One group, including AQP-1, exhibits a highly selective permeability to water. AQP-3, however, is one of several AQP that are also permeable to glycerol (31). The transport of water through these channels is selective but passive, the flux being driven by external forces such as those created by osmotic effects of macromolecules or ions. Accordingly, water transport through $\mathrm{AQP}$ occurs exclusively downstream any given gradient.

The physiologic role of AQP in the skin is not known. Matsuzaki et al. (32) stated that AQP-3 is present in many epithelial tissues and proposed that this AQP might provide the epithelial cells with water to protect them from dehydration. Our data on the distribution of AQP-1 and AQP-3 support the possibility that the AQP might have a physiologic role in the skin. The gene expression of the studied AQP is clearly higher in the fetus than in the adult. The birth process, the commencement of postnatal transepidermal water transport, and/or changes in skin hydration might be alternative trigger mechanisms for the changes in AQP expression. When a competent epidermal barrier has been formed, as in the mature skin, the AQP might indeed play a role in promoting hydration of the epidermis.

The barrier to water loss correlates with the integrity of the stratum corneum. In the extremely preterm neonate, the stratum corneum is structurally immature and functionally inadequate as a barrier. In the absence of a mature stratum corneum limiting water loss to the environment, the AQP might influence the rate of water transport through the skin by facilitating movement of water across the basal cell layers into the epidermis, resulting in a high water content in the skin and a high rate of water evaporation from the skin surface.

The calcium concentration has been shown to be an important regulator of epidermal differentiation (33), with low calcium levels in the basal parts and progressively higher levels toward the stratum corneum (34). Accordingly, AQP-mediated changes in the epidermal water content also have the potential, indirectly, to influence processes involved in the maturation of the epidermal barrier. Because AQP-3, besides its water transporting capacity, also allows passage of glycerol (31) and because significant de novo lipid synthesis takes place in the basal part of the epidermis $(35,36)$, transport of glycerol through AQP-3 might also have an impact on epidermal lipid synthesis and on the formation of the stratum corneum.

\section{CONCLUSIONS}

To summarize, AQP-1 and AQP-3 are distributed in locations where they can influence skin hydration and water transport. Their expression is higher in fetal skin than in the more mature skin. We speculate that AQP-1 and AQP-3 participate in the regulation of epidermal hydration and might contribute to high water losses through the immature skin. Our findings shed new light on AQP water channels as a possible mechanism involved in the regulation of the skin water content and in the pathophysiology of transepidermal water loss in the immature skin of infants born extremely preterm.

Acknowledgments. We thank Barbro Kjällström, Mette Vistisen, and Inger Merete Paulsen for expert technical assistance.

\section{REFERENCES}

1. Hammarlund K, Sedin G 1979 Transepidermal water loss in newborn infants. III Relation to gestational age. Acta Paediatr Scand 68:975-801

2. Thomas DB 1976 Hyperosmolarity and intraventricular haemorrhage in preterm babies. Acta Paediatr Scand 65:429-432

3. Lupton B, Roland EH, Whitfield MF, Hill A 1990 Serum sodium concentration and intraventricular hemorrhage in premature infants. Am J Dis Child 144:1019-1021

4. Hammarlund K, Sedin G, Strömberg B 1983 Transepidermal water loss in newborn infants. VIII. Relation to gestational age and post-natal age in appropriate and small for gestational age infants. Acta Paediatr Scand 72:721-728

5. Ågren J, Sjörs G, Sedin G 1998 Transepidermal water loss in infants born at 24 and 25 weeks of gestation. Acta Paediatr 87:1185-1190

6. Scheuplein RJ, Blank IH 1971 Permeability of the skin. Physiol Rev 51:702-747

7. Evans N, Rutter N 1986 Development of the epidermis in the newborn. Biol Neonate 49:74-80

8. Cartlidge Patrick HT, Rutter N 1992 Skin barrier function. In: Polin R, Fox W (eds) Fetal and neonatal physiology. Saunders, London, pp 569-585

9. Aszterbaum M, Menon GK, Feingold KR, Williams ML 1992 Ontogeny of the epidermal barrier to water loss in the rat: correlation of function with stratum corneum structure and lipid content. Pediatr Res 31:308-317

10. Meguro S, Arai Y, Masukawa Y, Uie K, Tokimitsu I 2000 Relationship between covalently bound ceramides and transepidermal water loss (TEWL). Arch Dermatol Res 292:463-468

11. Verkman AS, Van Hoek AN, Ma T, Frigeri A, Skach WR, Mitra A, Tamarappoo BK, Farinas J 1996 Water transport across mammalian cell membranes. Am J Physiol Cell Physiol 270:12-30

12. King LS, Agre P 1996 Pathophysiology of the aquaporin water channels. Annu Rev Physiol 58:649-668

13. Frigeri A, Gropper MA, Umenishi F, Kawashima M, Brown D, Verkman AS 1995 Localization of MIWC and GLIP water channel homologs in neuromuscular, epithelial and glandular tissues. J Cell Sci 108:2993-3002

14. Umeneshi F, Verkman AS, Gropper MA 1996 Quantitative analysis of aquaporin mRNA expression in rat tissues by Rnase protection assay. DNA Cell Biol 15:475480

15. Ågren J, Zelenin S, Håkansson M, Nielsen S, Aperia A, Sedin G 1999 Aquaporin-1 and -3 in perinatal skin. Pediatr Res 45:47A(abstr)

15a. Nielsen N, Smith BL, Christensen EI, Kneoper MA, Agre P 1993 CHIP28 water channels are localized in consitutively water-permeable segments of the nephron. J Cell Biol 120:371-383

15b. Nejsum LN $<$ Kwon TH, Jensen UB, Fumagalli O, Frokiaer J, Krane CM, Menon AG, King LS, Agre PC, Nieldsen S 2002 Functional requirement of aquaporin-5 in plasma membranes of sweat glands. Proc Natl Acad Sci USA 99:511-516

15c. Ecelbarger CA, Terris J, Frindt G, Echevarria M, Marples D, Nielsen S, Knepper MA 1995 Aquaporin-3 water channel localization and regulation in rat kidney. Am J Physiol Renal Physiol 269:663-672

16. Nielsen S, Di GS, Christensen EI, Knepper MA, Harris HW 1993 Cellular and subcellular immunolocalization of vasopressin-regulated water channels in rat kidney. Proc Natl Acad Sci U S A 92:11663-11667

17. Hammarlund K, Nilsson GE, Öberg PÅ, Sedin G 1977 Transepidermal water loss in newborn infants. I. Relation to ambient humidity and site of measurement and estimation of total transepidermal water loss. Acta Paediatr Scand 66:553-562

18. Nilsson GE 1977 Measurement of water exchange through the skin. Med Biol Eng Comput 15:209-218

19. Gabard B, Treffel P 1994 Hardware and measuring principle: the NOVA DPM 9003. In: Elsner P, Berardesca E, Maibach HI (eds) Bioengineering of the skin: water and the stratum corneum. CRC Press, Boca Raton, FL, pp 177-195

20. Jemec GB, Serup J 1990 Epidermal hydration and skin mechanics. The relationship between electrical capacitance and the mechanical properties of human skin in vivo. Acta Dermatol Venereol 70:245-247

21. Wickett RR, Nath V, Tanaka R, Hoath SB 1995 Use of continuous electrical capacitance and transepidermal water loss measurements for assessing barrier function in neonatal rat skin. Skin Pharmacol 8:179-185

22. Okah FA, Wickett RR, Pickens WL, Hoath SB 1995 Surface electrical capacitance as a noninvasive bedside measure of epidermal barrier maturation in the newborn infant. Pediatrics 96:688-692

23. Proksch E, Feingold KR, Mao-Qiang M, Elias PM 1991 Barrier function regulates epidermal lipid and DNA synthesis. J Clin Invest 87:1668-1673

24. Hanley K, Jiang Y, Elias P, Feingold K, Williams M 1997 Acceleration of barrier ontogenesis in vitro through air exposure. Pediatr Res 41:293-299 
25. Denda M, Sato J, Masuda Y, Tsuchiya T, Koyama J, Kuramoto M, Elias PM, Feingold KR 1998 Exposure to a dry environment enhances epidermal permeability barrier function. J Invest Dermatol 111:858-863

26. Sedin G 1996 Fluid management in the extremely preterm infant. In: Hansen TN, McIntosh N (eds) Current topics in neonatology. Saunders, London, pp 50-66

27. Preston GM, Agre P 1991 Isolation of the cDNA for erythrocyte integral membrane protein of 28 kilodaltons: member of an ancient channel family. Proc Natl Acad Sci U S A 88:11110-11114

28. Preston GM, Carroll TP, Guggino WB, Agre P 1992 Appearance of water channels in Xenopus oocytes expressing red cell CHIP28 protein. Science 256:385-387

29. Borgnia M, Nielsen S, Engel A, Agre P 1999 Cellular and molecular biology of the aquaporin water channels. Annu Rev Biochem 68:425-458

30. Agre P, Borgnia MJ, Yasui M, Neely JD, Carbrey J, Kozono D, Beitz E, Hoffert J, Leitch V, King LS 2001 Discovery of the aquaporins and their impact on basic and clinical physiology. Curr Top Membr 51:1-38

31. Ishibashi K, Sasaki S, Fushimi K, Uchida S, Kuwahara M, Saito H, Furukawa T, Nakajima K, Yamaguchi M, Gojobori T, Marumo F 1994 Molecular cloning and expression of a member of the aquaporin family with permeability to glycerol and urea in addition to water expressed at the basolateral membrane of kidney collecting duct cells. Proc Natl Acad Sci U S A 91:6269-6273

32. Matsuzaki T, Suzuki T, Koyama H, Tanaka S, Takata K 1999 Water channel protein AQP3 is present in epithelia exposed to the environment of possible water loss. J Histochem Cytochem 47:1275-1286

33. Elias PM, Nau P, Hanley K, Cullander C, Crumrine D, Bench G, Sideras-Haddad E, Mauro T, Williams ML, Feingold KR 1998 Formation of the epidermal calcium gradient coincides with key milestones of barrier ontogenesis in the rodent. J Invest Dermatol 110:399-404

34. Hoath SB, Pickens WL, Tanaka R, Ross R 1992 Ontogeny of integumental calcium in relation to surface area and skin water content in the perinatal rat. J Appl Physiol 73:458-464

35. Feingold KR, Wiley MH, MacRae G, Lear S, Moser AH, Zsigmond G, Siperstein MD 1983 De novo sterologenesis in the intact rat Metabolism 32:75-81

36. Monger DJ, Williams ML, Feingold KR, Brown BE, Elias PM 1988 Localization of sites of lipid biosynthesis in mammalian epidermis. J Lipid Res 29:603-612 